\title{
Intermittent Hypoxia Severity in Animal Models of Sleep Apnea
}

\author{
Ramon Farré ${ }^{1,2,3 *}$, Josep M. Montserrat ${ }^{2,3,4}$, David Gozal $^{5}$, Isaac Almendros ${ }^{1,2,3}$ and \\ Daniel Navajas ${ }^{1,2,6}$ \\ 1 Unitat de Biofísica i Bioenginyeria, Facultat de Medicina i Ciències de la Salut, Universitat de Barcelona, Barcelona, Spain, \\ ${ }^{2}$ CIBER de Enfermedades Respiratorias, Madrid, Spain, ${ }^{3}$ Institut Investigacions Biomèdiques August Pi Sunyer, Barcelona, \\ Spain, ${ }^{4}$ Sleep Lab, Hospital Clínic de Barcelona, Barcelona, Spain, ${ }^{5}$ Department of Child Health, University of Missouri \\ School of Medicine, Columbia, MO, United States, ${ }^{6}$ Institute for Bioengineering of Catalonia, The Barcelona Institute of \\ Science and Technology, Barcelona, Spain
}

Keywords: intermittent hypoxia, oxygen dissociation curve, hypoxia/reoxygenation, sleep breathing disorders, disease model animal, obstructive sleep apnea syndrome

Obstructive sleep apnea (OSA) is a very prevalent breathing disorder (Peppard et al., 2013; Heinzer et al., 2015) characterized by recurrent obstructions of the upper airway during sleep. These obstructions, which can present as either frank apneas or hypopneas, result in cyclic events of arterial hypoxemia with or without hypercapnia since blood circulating through lung capillaries during the obstructive events does not receive the required amount of oxygen because interrupted ventilation reduces the partial pressure of oxygen $\left(\mathrm{PO}_{2}\right)$ in alveolar air. Intermittent arterial

OPEN ACCESS

Edited by:

Yu Ru Kou,

National Yang-Ming University, Taiwan

Reviewed by:

Takashi Ono,

Tokyo Medical and Dental University,

Japan

Sayoko Ogura,

Nihon University, Japan

${ }^{*}$ Correspondence: Ramon Farré

rfarre@ub.edu

Specialty section:

This article was submitted to Respiratory Physiology, a section of the journal Frontiers in Physiology

Received: 25 August 2018 Accepted: 17 October 2018 Published: 06 November 2018

Citation:

Farré R, Montserrat JM, Gozal D,

Almendros I and Navajas D (2018) Intermittent Hypoxia Severity in Animal Models of Sleep Apnea.

Front. Physiol. 9:1556.

doi: 10.3389/fphys.2018.01556 hypoxemia immediately translates into the systemic capillary circulation with the result that all patient's tissues are subjected to cycles of hypoxia/reoxygenation of varying severity (Almendros et al., 2010, 2011, 2013; Reinke et al., 2011; Torres et al., 2014; Moreno-Indias et al., 2015). There is now ample experimental and epidemiological evidence that the oxidative stress and inflammatory cascades elicited at both systemic and tissue levels by the recurrent hypoxia-reoxygenation events are major drivers of the clinically relevant morbid consequences of OSA (Lavie, 2015), namely increased risk of cardiovascular, metabolic, neurocognitive and malignant diseases (Lévy et al., 2015). Given the major health care burden posed by OSA and the ethical impossibility of carrying out precise mechanistic studies focused on causality in patients with OSA, considerable efforts have been preferentially focused on animal models of OSA (Davis and O'Donnell, 2013; Chopra et al., 2016) and more particularly on those mimicking intermittent hypoxemia.

To realistically model intermittent hypoxemia in OSA it is important to bear in mind that the potential effect of this exposure depends on the magnitude of the decrease in arterial oxygen partial pressure $\left(\mathrm{PaO}_{2}\right)$, since this biological variable de facto determines the $\mathrm{PO}_{2}$ gradient across the capillary membrane, and hence oxygen delivery to cells within the various tissues. In practice, the conventional setting for subjecting animals to intermittent hypoxia consists of cyclically changing the oxygen fraction $\left(\mathrm{FiO}_{2}\right)$ in the environmental gas breathed by the animals from room air $\left(\mathrm{F}_{\mathrm{I}} \mathrm{O}_{2}\right.$ - 21\%) to different nadir values ranging from $\mathrm{F}_{\mathrm{I}} \mathrm{O}_{2}$ of 4 to $15 \%$, and thus model different degrees of hypoxia severity which, as would be anticipated, yield dose-response effects (Nagai et al., 2014; Lim et al., 2016; Gallego-Martin et al., 2017; Docio et al., 2018). When using this experimental setting the degree of intermittent hypoxemia achieved for a given $\mathrm{FiO}_{2}$ swing is similar in young and old animals (Dalmases et al., 2014) which is interesting given that the effects of hypoxia/reoxygenation are modulated by age (Torres et al., 2018). The conventional settings used for applying intermittent hypoxia to animals include two major parameters, with one of them being the frequency of hypoxic events [which loosely corresponds to the clinical index of apnea-hypopnea index (AHI) recorded in polysomnographic studies of patients with OSA, Berry et al., 2018]. Setting the frequency of intermittent hypoxia to mimic different values of AHI is a relatively straightforward proposition, and different investigators have carried out animal experiments in which they modeled varying 
rates of hypoxic events such as to cover a wide range of AHI, e.g., from the highest events rates in OSA patients (60 events/h) to occasional events ( 2 events/h) (Almendros et al., 2013; Shiota et al., 2013; Dalmases et al., 2014; Jun et al., 2014; BriançonMarjollet et al., 2016; Gozal et al., 2017). Moreover, at any given frequency of cycling it is also simple to prescribe different durations for the de-oxygenation and re-oxygenation phases within each cycle (Chodzynski et al., 2013; Lim et al., 2015).

The second major index defining the characteristics of the experimental OSA paradigm is the severity of the hypoxic stimulus within each event. Determining the severity of the actual intermittent hypoxemia in OSA patients by measuring the variable which is physiologically relevant in terms of oxygen transport to tissues in systemic capillaries $\left(\mathrm{PaO}_{2}\right)$ is not easy, particularly when taking into account that in OSA this variable changes at a high frequency. Such real time measurements would only be possible if using fast fiberoptic oxygen sensors suitable for human use and capable of continually measure fast variations of oxygen partial pressure in blood (Formenti et al., 2015) or by a technique of repetitive blood sampling along the obstructive events as carried out in animals (Lee et al., 2009). However, such invasive or complex measurements are clearly not appropriate for OSA patients in clinical settings, especially when considering that indirect estimates of $\mathrm{PaO}_{2}$ can be easily and non-invasively obtained by means of pulse oximetry. Indeed, this technique -which provides real time measurement of $\mathrm{SaO}_{2}$ (i.e., the percentage of oxy-hemoglobin in arterial blood within each heartbeat) - is an accurate surrogate of $\mathrm{PaO}_{2}$ since for conventional conditions (e.g., $\mathrm{pH}$, temperature) the oxygen dissociation curve of human blood provides a direct relationship between $\mathrm{PaO}_{2}$ and $\mathrm{SaO}_{2}$ (Severinghaus, 1979). Given the ease of its measurement, pulse oximetry is currently the standard tool to clinically quantify the severity and duration of hypoxic events in OSA patients (Berry et al., 2018). Fortunately, pulse oximetry can be also applied to measure $\mathrm{SaO}_{2}$ in animals. Indeed, given that hemoglobin from different species presents virtually the same absorption properties in the visible and near infrared regions (Grosenbaugh et al., 1997), pulse oximeters for small animals only require software adaptations to deal with much higher heart rate frequencies than in humans, even if they make inferential assumptions and annul considerations regarding potential differences across saturation equations in rodents. Nevertheless, characterizing the depth of the hypoxemic events in animal models of OSA and compare them with those in patients is not straightforward, and constitutes a controversial issue in sleep apnea research. Furthermore, the potential presence of hemodynamic instability, tissue perfusion changes, and accuracy issues of oximeters at the low ranges of saturation need to be considered as well. This Opinion article aims to contribute to this topic discussion by illustrating important considerations and evidence in this contextual setting.

The major controversial point refers to one of the most commonly employed paradigms of intermittent hypoxia when applied to mice, and resulting in measured $\mathrm{SaO}_{2}$ swings with nadir values in the range 50-70\% (Jun et al., 2010; Reinke et al., 2011; Torres et al., 2014, 2015; Lim et al., 2015, 2016). Specifically, in a recent review focused on sleep apnea research

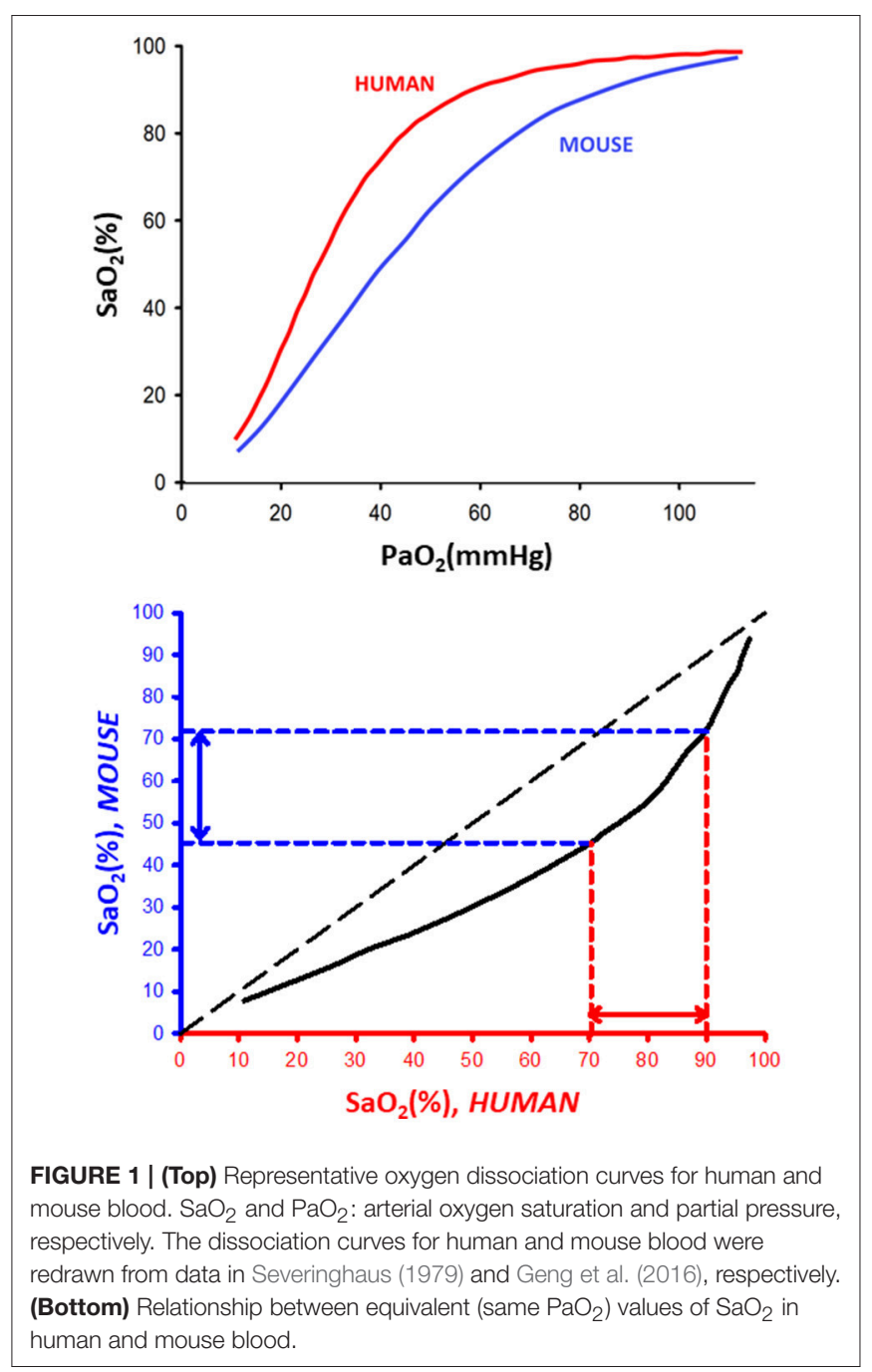

in animals, it was stated that such intermittent hypoxia profiles may result in significantly more severe hypoxic events than those typically experienced by patients with OSA, in whom $\mathrm{SaO}_{2}$ nadir ranges of $77-90 \%$ are usually documented (Lim et al., 2015), and that therefore extrapolation from murine models to human disease should be applied with caution (Chopra et al., 2016). As will become apparent from the following discussion, we disagree with such an objection, and instead state that such low $\mathrm{SaO}_{2}$ nadirs (50-70\%) in mice realistically mimic the hypoxemic events in patients since they actually correspond to $\mathrm{PaO}_{2}$ values similar to those in OSA patients. The rationale behind such assertion is that $\mathrm{SaO}_{2}$ is misleading when comparing severity of hypoxemia across different species because the oxygen dissociation curve in mice is considerably different from humans, and this point will be reinforced while we elaborate on wellestablished physiological data depicting oxygen dissociation curves across species.

The top of Figure 1 shows a representation of the typical $\mathrm{SaO}_{2}-\mathrm{PaO}_{2}$ relationships in human (red line) and mouse (blue line). The usually overlooked fundamental fact that there is 
a shift of the oxygen dissociation curve toward the right as the body size of the species decreases was already firmly established 60 years ago (Schmidt-Neilsen and Larimer, 1958). More specifically, half-saturation pressure $\left(\mathrm{P}_{50}\right)$, defined as $\mathrm{PaO}_{2}$ corresponding to $\mathrm{SaO}_{2}=50 \%$, and typical body weight (BW) of any mammalian species were shown to be closely prescribed by a classical heterogonic relationship (Adolph, 1949) in biological scaling (Schmidt-Nielsen, 1970): $\mathrm{P}_{50}=50.34 \times$ $\mathrm{BW}^{-0.054}\left(\mathrm{P}_{50}\right.$ in $\mathrm{mmHg}, \mathrm{BW}$ in grams), for a range of mammals encompassing horse to mouse (Schmidt-Neilsen and Larimer, 1958). It is also remarkable that the Bohr effect (shifting of the dissociation curve as blood $\mathrm{CO}_{2} / \mathrm{pH}$ increases/decreases) applies to mammalian blood with a magnitude range that also closely follows a heterogonic relationship (Riggs, 1960), a factor that could further amplify the human-mouse difference, particularly when $\mathrm{CO}_{2}$ increases during obstructive apneas are taken into account (Farré et al., 2007). Interestingly, the earlier reports on detectable differences among hemoglobin dissociation curves in human and mouse blood have been subsequently confirmed as measurement techniques have improved (Gray and Steadman, 1964; Severinghaus, 1979; Mouneimne et al., 1990; Geng et al., 2016). Figure 1 (top) clearly shows that for any given $\mathrm{SaO}_{2}$ value, $\mathrm{PaO}_{2}$ is always lower for human than for mouse blood. In other words, mice have more oxygen reserve than humans. These data can be plotted as the relationship between $\mathrm{SaO}_{2}$ in mice and humans for any value of $\mathrm{PaO}_{2}$ as shown in the bottom panel of Figure 1, illustrating that $\mathrm{SaO}_{2}$ in mice is always below the identity line. This figure shows that the typical range of $\mathrm{SaO}_{2}$ nadir values in patients (70-90\%) corresponds to nadir $\mathrm{SaO}_{2}$ values in the range $45-72 \%$ in mice, thereby firmly confirming

\section{REFERENCES}

Adolph, E. F. (1949). Quantitative relations in the physiological constitutions of mammals. Science 109, 579-585.

Almendros, I., Farré, R., Planas, A. M., Torres, M., Bonsignore, M. R., Navajas, D., et al. (2011). Tissue oxygenation in brain, muscle, and fat in a rat model of sleep apnea: differential effect of obstructive apneas and intermittent hypoxia. Sleep 34, 1127-1133. doi: 10.5665/SLEEP.1176

Almendros, I., Montserrat, J. M., Torres, M., Dalmases, M., Cabañas, M. L., Campos-Rodríguez, F., et al. (2013). Intermittent hypoxia increases melanoma metastasis to the lung in a mouse model of sleep apnea. Respir. Physiol. Neurobiol. 186, 303-307. doi: 10.1016/j.resp.2013.03.001

Almendros, I., Montserrat, J. M., Torres, M., González, C., Navajas, D., and Farré, R. (2010). Changes in oxygen partial pressure of brain tissue in an animal model of obstructive apnea. Respir. Res. 11:3. doi: 10.1186/1465-9921-11-3

Berry, R. B., Altertario, C. L., Harding, S. M., Llyod, R. M., Plante, D. T., Quan, S. F., et al. (2018). The AASM Manual for the Scoring of Sleep and Associated Events: rules, Terminology and Technical Specifications. Version 2.5. Darin, IL: America Academy of Sleep Medicine.

Briançon-Marjollet, A., Monneret, D., Henri, M., Hazane-Puch, F., Pepin, J. L., Faure, P., et al. (2016). Endothelin regulates intermittent hypoxia-induced lipolytic remodelling of adipose tissue and phosphorylation of hormonesensitive lipase. J. Physiol. 594, 1727-1740. doi: 10.1113/JP271321

Chodzynski, K. J., Conotte, S., Vanhamme, L., Van Antwerpen, P., Kerkhofs, M., Legros, J. L., et al. (2013). A new device to mimic intermittent hypoxia in mice. PLoS ONE 8:e59973. doi: 10.1371/journal.pone.0059973

Chopra, S., Polotsky, V. Y., and Jun, J. C. (2016). Sleep apnea research in animals. Past, present, and future. Am. J. Respir. Cell Mol. Biol. 54, 299-305. doi: $10.1165 / \mathrm{rcmb} .2015-0218 \mathrm{TR}$ the adequacy of current experimental environmental hypoxia protocols used in murine models.

In conclusion, to achieve $\mathrm{PaO}_{2}$ nadir values similar to those traditionally experienced by severe OSA patients -i.e., to realistically simulate patients' hypoxia- $\mathrm{SaO}_{2}$ in mice should be much lower than the $\mathrm{SaO}_{2}$ observed in patients. These considerations substantiate our initial objection to the statement by Chopra and coauthors (Chopra et al., 2016) that the currently used experimental paradigms of intermittent hypoxia $\left(\mathrm{SaO}_{2}\right.$ swings with nadir $50-70 \%$ ) in mice are not at all excessively severe, but rather closely match human conditions. Therefore, current intermittent hypoxia exposure paradigms adequately and reliably perform when subjecting mouse cells in the various tissues to a realistic hypoxia/reoxygenation challenge that enables investigation of mechanisms underlying the end-organ adverse consequences of OSA.

\section{AUTHOR CONTRIBUTIONS}

RF conceived and drafted the manuscript. JM, DG, IA, and DN provided their expertise in animal models, respiratory physiology and pathophysiology of sleep apnea, and significantly contributed to write the final version.

\section{ACKNOWLEDGMENTS}

This work was supported in part by the Spanish Ministry of Economy and Competitiveness (SAF2017-85574-R, DPI201783721-P; AEI/FEDER, UE) and Generalitat de Catalunya (CERCA Program).

Dalmases, M., Torres, M., Márquez-Kisinousky, L., Almendros, I., Planas, A. M., Embid, C., et al. (2014). Brain tissue hypoxia and oxidative stress induced by obstructive apneas is different in young and aged rats. Sleep 37, 1249-1256. doi: $10.5665 /$ sleep. 3848

Davis, E. M., and O'Donnell, C. P. (2013). Rodent models of sleep apnea. Respir. Physiol. Neurobiol. 188, 355-361. doi: 10.1016/j.resp.2013.05.022

Docio, I., Olea, E., Prieto-LLoret, J., Gallego-Martin, T., Obeso, A., GomezNiño, A., et al. (2018). Guinea pig as a model to study the carotid body mediated chronic intermittent hypoxia effects. Front. Physiol. 9:694. doi: 10.3389/fphys.2018.00694

Farré, R., Nácher, M., Serrano-Mollar, A., Gáldiz, J. B., Alvarez, F. J., Navajas, D., et al. (2007). Rat model of chronic recurrent airway obstructions to study the sleep apnea syndrome. Sleep 30, 930-933.

Formenti, F., Chen, R., McPeak, H., Murison, P. J., Matejovic, M., Hahn, C. E., et al. (2015). Intra-breath arterial oxygen oscillations detected by a fast oxygen sensor in an animal model of acute respiratory distress syndrome. Br. J. Anaesth. 114, 683-688. doi: 10.1093/bja/aeu407

Gallego-Martin, T., Farré, R., Almendros, I., Gonzalez-Obeso, E., and Obeso, A. (2017). Chronic intermittent hypoxia mimicking sleep apnoea increases spontaneous tumorigenesis in mice. Eur. Respir. J. 49:1602111. doi: 10.1183/13993003.02111-2016

Geng, X., Dufu, K., Hutchaleelaha, A., Xu, Q., Li, Z., Li, C. M., et al. (2016). Increased hemoglobin-oxygen affinity ameliorates bleomycininduced hypoxemia and pulmonary fibrosis. Physiol. Rep. 4:e12965. doi: 10.14814/phy2.12965

Gozal, D., Khalyfa, A., Qiao, Z., Almendros, I., and Farré, R. (2017). Temporal trajectories of novel object recognition performance in mice exposed to intermittent hypoxia. Eur. Respir. J. 50:1701456. doi: 10.1183/13993003.01456-2017 
Gray, L. H., and Steadman, J. M. (1964). Determination of the oxyhaemoglobin dissociation curves for mouse and rat blood. J. Physiol. 175, 161-171.

Grosenbaugh, D. A., Alben, J. O., and Muir, W. W. (1997). Absorbance spectra of inter-species hemoglobins in the visible and near infrared regions. J. Vet. Emerg. $7,36-42$.

Heinzer, R., Vat, S., Marques-Vidal, P., Marti-Soler, H., Andries, D., Tobback, N., et al. (2015). Prevalence of sleep-disordered breathing in the general population: the HypnoLaus study. Lancet Respir. Med. 3, 310-318. doi: 10.1016/S2213-2600(15)00043-0

Jun, J., Reinke, C., Bedja, D., Berkowitz, D., Bevans-Fonti, S., Li, J., et al. (2010). Effect of intermittent hypoxia on atherosclerosis in apolipoprotein E-deficient mice. Atherosclerosis 209, 381-386. doi: 10.1016/j.atherosclerosis.2009.10.017

Jun, J. C., Shin, M. K., Devera, R., Yao, Q., Mesarwi, O., Bevans-Fonti, S., et al. (2014). Intermittent hypoxia-induced glucose intolerance is abolished by $\alpha$ adrenergic blockade or adrenal medullectomy. Am. J. Physiol. Endocrinol. Metab. 307, E1073-E1083. doi: 10.1152/ajpendo.00373.2014

Lavie, L. (2015). Oxidative stress in obstructive sleep apnea and intermittent hypoxia-revisited-the bad ugly and good: implications to the heart and brain. Sleep Med. Rev. 20, 27-45. doi: 10.1016/j.smrv.2014.07.003

Lee, E. J., Woodske, M. E., Zou, B., and O'Donnell, C. P. (2009). Dynamic arterial blood gas analysis in conscious, unrestrained C57BL/6J mice during exposure to intermittent hypoxia. J. Appl. Physiol. 107, 290-294. doi: 10.1152/japplphysiol.91255.2008

Lévy, P., Kohler, M., McNicholas, W. T., Barbé, F., McEvoy, R. D., Somers, V. K., et al. (2015). Obstructive sleep apnoea syndrome. Nat. Rev. Dis. Prim. 1:15015. doi: 10.1038/nrdp.2015.15

Lim, D. C., Brady, D. C., Po, P., Chuang, L. P., Marcondes, L., Kim, E. Y., et al. (2015). Simulating obstructive sleep apnea patients' oxygenation characteristics into a mouse model of cyclical intermittent hypoxia. J. Appl. Physiol. 118, 544-557. doi: 10.1152/japplphysiol.00629.2014

Lim, D. C., Brady, D. C., Soans, R., Kim, E. Y., Valverde, L., Keenan, B. T., et al. (2016). Different cyclical intermittent hypoxia severities have different effects on hippocampal microvasculature. J. Appl. Physiol. 121, 78-88. doi: 10.1152/japplphysiol.01040.2015

Moreno-Indias, I., Torres, M., Montserrat, J. M., Sanchez-Alcoholado, L., Cardona, F., Tinahones, F. J., et al. (2015). Intermittent hypoxia alters gut microbiota diversity in a mouse model of sleep apnoea. Eur. Respir. J. 45, 1055-1065. doi: 10.1183/09031936.00184314

Mouneimne, Y., Barhoumi, R., Myers, T., Slogoff, S., and Nicolau, C. (1990). Stable rightward shifts of the oxyhemoglobin dissociation curve induced by encapsulation of inositol hexaphosphate in red blood cells using electroporation. FEBS Lett. 275, 117-120.

Nagai, H., Tsuchimochi, H., Yoshida, K., Shirai, M., and Kuwahira, I. (2014). A novel system including an $\mathrm{N}_{2}$ gas generator and an air compressor for inducing intermittent or chronic hypoxia. Int. J. Clin. Exp. Physiol. 1, 307-310. doi: $10.4103 / 2348-8093.149770$
Peppard, P. E., Young, T., Barnet, J. H., Palta, M., Hagen, E. W., and Hla, K. M. (2013). Increased prevalence of sleep-disordered breathing in adults. Am. J. Epidemiol. 177, 1006-1014. doi: 10.1093/aje/ kws342

Reinke, C., Bevans-Fonti, S., Drager, L. F., Shin, M. K., and Polotsky, V. Y. (2011). Effects of different acute hypoxic regimens on tissue oxygen profiles and metabolic outcomes. J. Appl. Physiol. 111, 881-890. doi: 10.1152/japplphysiol.00492.2011

Riggs, A. (1960). The nature and significance of the Bohr effect in mammalian hemoglobins. J. Gen. Physiol. 43, 737-752.

Schmidt-Neilsen, K., and Larimer, J. L. (1958). Oxygen dissociation curves of mammalian blood in relation to body size. Am. J. Physiol. 195, 424-428.

Schmidt-Nielsen, K. (1970). Energy metabolism, body size, and problems of scaling. Fed. Proc. 29, 1524-1532.

Severinghaus, J. W. (1979). Simple, accurate equations for human blood O2 dissociation computations. J. Appl. Physiol. Respir. Environ. Exerc. Physiol. 46, 599-602.

Shiota, S., Takekawa, H., Matsumoto, S. E., Takeda, K., Nurwidya, F., Yoshioka, Y., et al. (2013). Chronic intermittent hypoxia/reoxygenation facilitate amyloid$\beta$ generation in mice. J. Alzheimers. Dis. 37, 325-333. doi: 10.3233/JAD-1 30419

Torres, M., Campillo, N., Nonaka, P. N., Montserrat, J. M., Gozal, D., MartínezGarcía, M. A., et al. (2018). Aging reduces intermittent hypoxia-induced lung carcinoma growth in a mouse model of sleep apnea. Am. J. Respir. Crit. Care Med. doi: 10.1164/rccm.201805-0892LE. [Epub ahead of print].

Torres, M., Laguna-Barraza, R., Dalmases, M., Calle, A., Pericuesta, E., Montserrat, J. M., et al. (2014). Male fertility is reduced by chronic intermittent hypoxia mimicking sleep apnea in mice. Sleep 37, 1757-1765. doi: 10.5665/ sleep.4166

Torres, M., Rojas, M., Campillo, N., Cardenes, N., Montserrat, J. M., Navajas, D., et al. (2015). Parabiotic model for differentiating local and systemic effects of continuous and intermittent hypoxia. J. Appl. Physiol. 118, 42-47. doi: 10.1152/japplphysiol.00858.2014

Conflict of Interest Statement: The authors declare that the research was conducted in the absence of any commercial or financial relationships that could be construed as a potential conflict of interest.

Copyright (๑) 2018 Farré, Montserrat, Gozal, Almendros and Navajas. This is an open-access article distributed under the terms of the Creative Commons Attribution License (CC BY). The use, distribution or reproduction in other forums is permitted, provided the original author $(s)$ and the copyright owner(s) are credited and that the original publication in this journal is cited, in accordance with accepted academic practice. No use, distribution or reproduction is permitted which does not comply with these terms. 